\title{
The TRIM-NHL Protein Brat Promotes Axon Maintenance by Repressing $\operatorname{src} 64 B$ Expression
}

\author{
Giovanni Marchetti, ${ }^{1}$ Ilka Reichardt, ${ }^{2}$ Juergen A. Knoblich, ${ }^{2}$ and Florence Besse ${ }^{1}$ \\ ${ }^{1}$ Institute of Biology Valrose, University of Nice Sophia Antipolis, CNRS UMR7277, INSERM U1091, 06108 Nice Cedex 2, France and ${ }^{2}$ Institute of Molecular \\ Biotechnology of the Austrian Academy of Sciences (IMBA), 1030 Vienna, Austria
}

\begin{abstract}
The morphology and the connectivity of neuronal structures formed during early development must be actively maintained as the brain matures. Although impaired axon stability is associated with the progression of various neurological diseases, relatively little is known about the factors controlling this process. We identified Brain tumor (Brat), a conserved member of the TRIM-NHL family of proteins, as a new regulator of axon maintenance in Drosophila CNS. Brat function is dispensable for the initial growth of Mushroom Body axons, but is required for the stabilization of axon bundles. We found that Brat represses the translation of $\operatorname{src} 64 B$, an upstream regulator of a conserved Rho-dependent pathway previously shown to promote axon retraction. Furthermore, brat phenotypes are phenocopied by $\operatorname{src} 64 B$ overexpression, and partially suppressed by reducing the levels of $s r c 64 B$ or components of the Rho pathway, suggesting that brat promotes axon maintenance by downregulating the levels of Src64B. Finally, Brat regulates brain connectivity via its NHL domain, but independently of its previously described partners Nanos, Pumilio, and d4EHP. Thus, our results uncover a novel post-transcriptional regulatory mechanism that controls the maintenance of neuronal architecture by tuning the levels of a conserved rho-dependent signaling pathway.
\end{abstract}

Key words: axon maintenance; Drosophila; mushroom body; post-transcriptional

\section{Introduction}

Neuronal circuitries established during early development face several challenges during brain maturation (Bénard and Hobert, 2009). First, they maintain their morphology and connectivity in an environment undergoing extensive changes in its mechanical and molecular properties. Second, they keep a certain flexibility to support structural plasticity in response to stimulation, a process essential for the formation and storage of memory traces. Although the mechanisms underlying the maintenance of neuronal circuits have received much less attention than those involved in the establishment of circuits, their alterations appear to be crucial for the progression of neurodegenerative diseases (Luo and O'Leary, 2005).

To identify new genes involved in the formation and/or maintenance of axonal processes, we have used Drosophila Mushroom Body $(\mathrm{MB})$ as a model system. MBs are symmetric structures essential for high-order functions (Heisenberg, 2003). MB neu-

Received Aug. 1, 2013; revised Aug. 30, 2014; accepted Sept. 4, 2014.

Author contributions: G.M., I.R., J.A.K., and F.B. designed research; G.M., I.R., and F.B. performed research; G.M., I.R., J.A.K., and F.B. analyzed data; G.M. and F.B. wrote the paper.

This study was supported by grants (ATIP/CNRS 2008, FRM Implantation Nouvelles Equipes, ARC Fixe, HFSP Career Development Award, ANR JCIC) to F.B. Work in J.K.'s lab is supported by the Austrian Academy of Sciences, the Austrian Science Fund (FWF, grants I_552-B19 and Z_153_B09), and an advanced grant of the European Research Council. We are grateful to J.M. Dura and members of the Besse and Noselli groups for discussions and to C. Medioni, F. De Graeve, and G. Tavosanis for critical reading of this manuscript. We thank the PRISM Imaging Facility for use of their microscopes and support, and $G$. Tavosanis for allowing some of the last stages of this work to be performed in her laboratory.

The authors declare no competing financial interests.

Correspondence should be addressed to Florence Besse, Institute of Biology Valrose, University of Nice Sophia Antipolis, CNRS UMR 7277, INSERM U1091, Parc Valrose, 06108 Nice Cedex 2, France. E-mail: besse@unice.fr.

DOI:10.1523/JNEUROSCI.3285-13.2014

Copyright $\odot 2014$ the authors $\quad 0270-6474 / 14 / 3413855-10 \$ 15.00 / 0$ ron cell bodies are located in the posterior cortex, and extend their axons anteroventrally, forming a fiber called peduncle. Anteriorly, $\mathrm{MB}$ axons bifurcate to form a dorsal and a medial lobe. Each $\mathrm{MB}$ is composed of three types of neurons $\left(\alpha \beta, \alpha^{\prime} \beta^{\prime}\right.$, and $\left.\gamma\right)$ generated sequentially during development: $\gamma$ neurons are generated during embryogenesis and early larval stages, $\alpha^{\prime} \beta^{\prime}$ neurons during late larval stages, and $\alpha \beta$ during early metamorphosis (Lee et al., 1999). $\gamma$ neurons undergo a specific remodeling program, as $\gamma$ larval medial and dorsal axonal branches are pruned during early metamorphosis, and replaced by a main branch extending medially (Lee et al., 1999; Watts et al., 2003).

In this system, we have identified the tumor-suppressor gene brain tumor (brat) as a novel regulator of axon maintenance. Brat belongs to the tripartite motif (TRIM)-NHL family of proteins, which have been implicated in the regulation of various biological processes (Wulczyn et al., 2011). Similarly to its mammalian ortholog, TRIM32, Brat has, for example, been shown to control the proliferation and differentiation of specific neural precursor lineages during early neuronal development (Bowman et al., 2008; Schwamborn et al., 2009). Here, we show that brat function does not regulate the specification or the initial growth of $\mathrm{MB}$ axons, but is required for the maintenance of $\mathrm{MB}$ axons. Interestingly, brat phenotypes are partially suppressed by reducing the dose of components of a conserved Rho-dependent pathway shown to promote axon retraction (Billuart et al., 2001). Furthermore, elevated levels of Src64B, an upstream regulator of this pathway, are not only observed in brat mutant context, but also sufficient to trigger axon retraction, suggesting that Brat prevents axon retraction by keeping the levels of Src64B low. Finally, we genetically demonstrate that Brat is acting independently of its previously described partners Nanos, Pumilio, and d4EHP to 

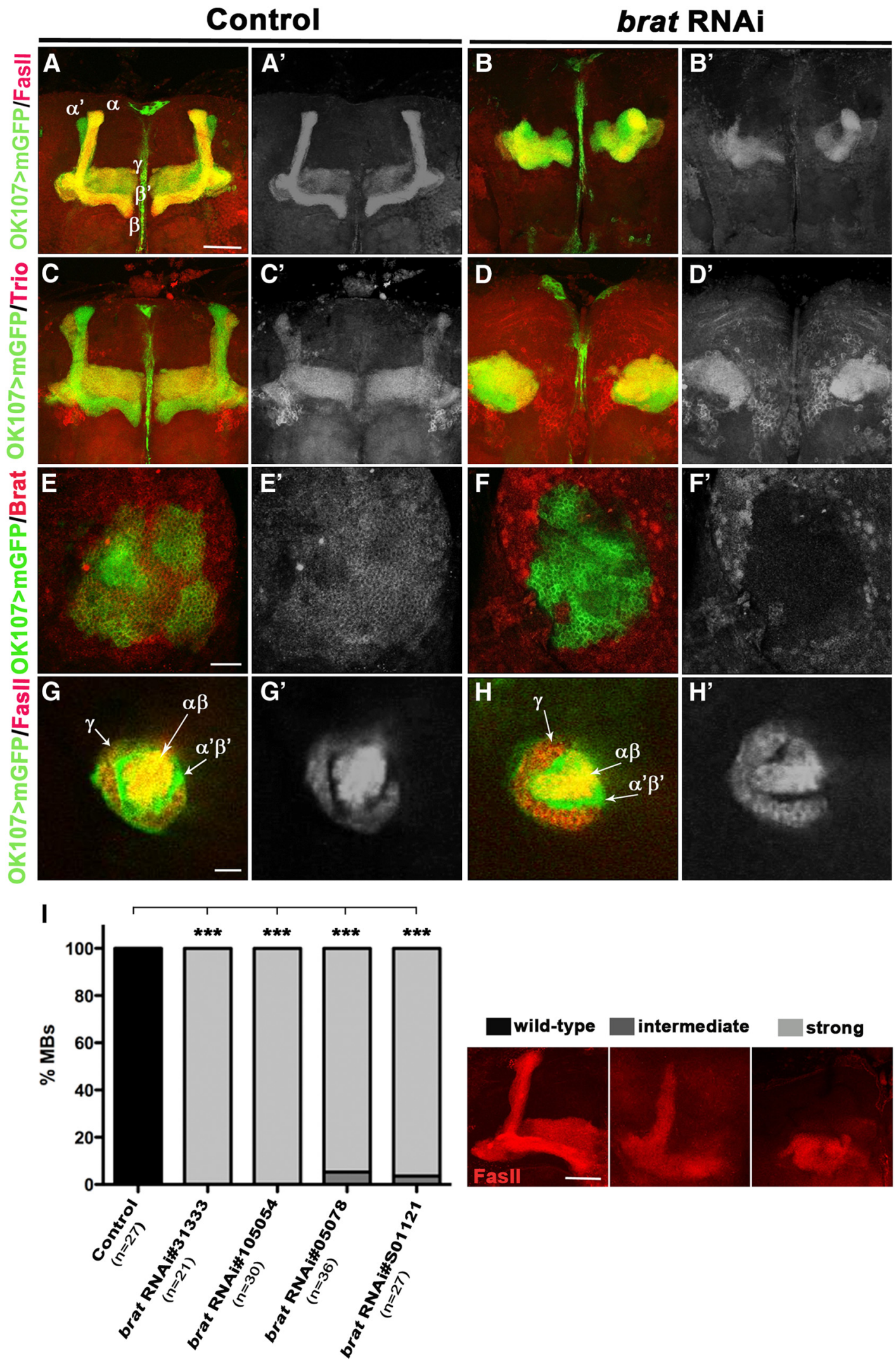

Figure 1. brat downregulation disrupts MB axon morphology. $\boldsymbol{A}-\boldsymbol{D}^{\prime}$, Adult MB lobes from control $(\boldsymbol{A}, \boldsymbol{C})$ and brat RNAi $(\boldsymbol{B}, \boldsymbol{D})$ brains stained with anti-Fasll $\left(\boldsymbol{A}-\boldsymbol{B}^{\prime}\right)$ or anti-Trio $\left(\boldsymbol{C}-\boldsymbol{D}^{\prime}\right)$ antibodies (red in the overlay). Scale bar, $50 \mu \mathrm{m} . \boldsymbol{E}-\boldsymbol{F}^{\prime}$, Cell bodies of control $\left(\boldsymbol{E}, \boldsymbol{E}^{\prime}\right)$ and brat RNAi $\left(\boldsymbol{F}, \boldsymbol{F}^{\prime}\right)$ adult MB neurons stained with anti-Brat antibodies (red in the overlay). Scale bar, $50 \mu \mathrm{m} . \mathbf{G}-\boldsymbol{H}^{\prime}$, (ross sections of control $\left(\mathbf{G}, \boldsymbol{G}^{\prime}\right)$ and brat RNAi $\left(\boldsymbol{H}, \boldsymbol{H}^{\prime}\right)$ adult MB peduncles stained with anti-Fasll antibodies (red in the overlay). Arrows point to the three different subpopulations of axons organized in concentric layers. Scale bar, $10 \mu \mathrm{m}$. Green in $\boldsymbol{A}-\boldsymbol{H}^{\prime}$ : OK107-GAL4-driven mCD8::GFP. I, Left, Percentages of adult MBs exhibiting wild-type, intermediate, or strong axonal defects in four different brat RNAi lines. Numbers correspond to the total number of scored MBs. Right, Representative images of the three phenotypic categories (based on Fasll staining). Statistical comparisons to the control: ${ }^{* * *} p<0.001$ (Fisher's exact test). Scale bar, $20 \mu \mathrm{m}$. 

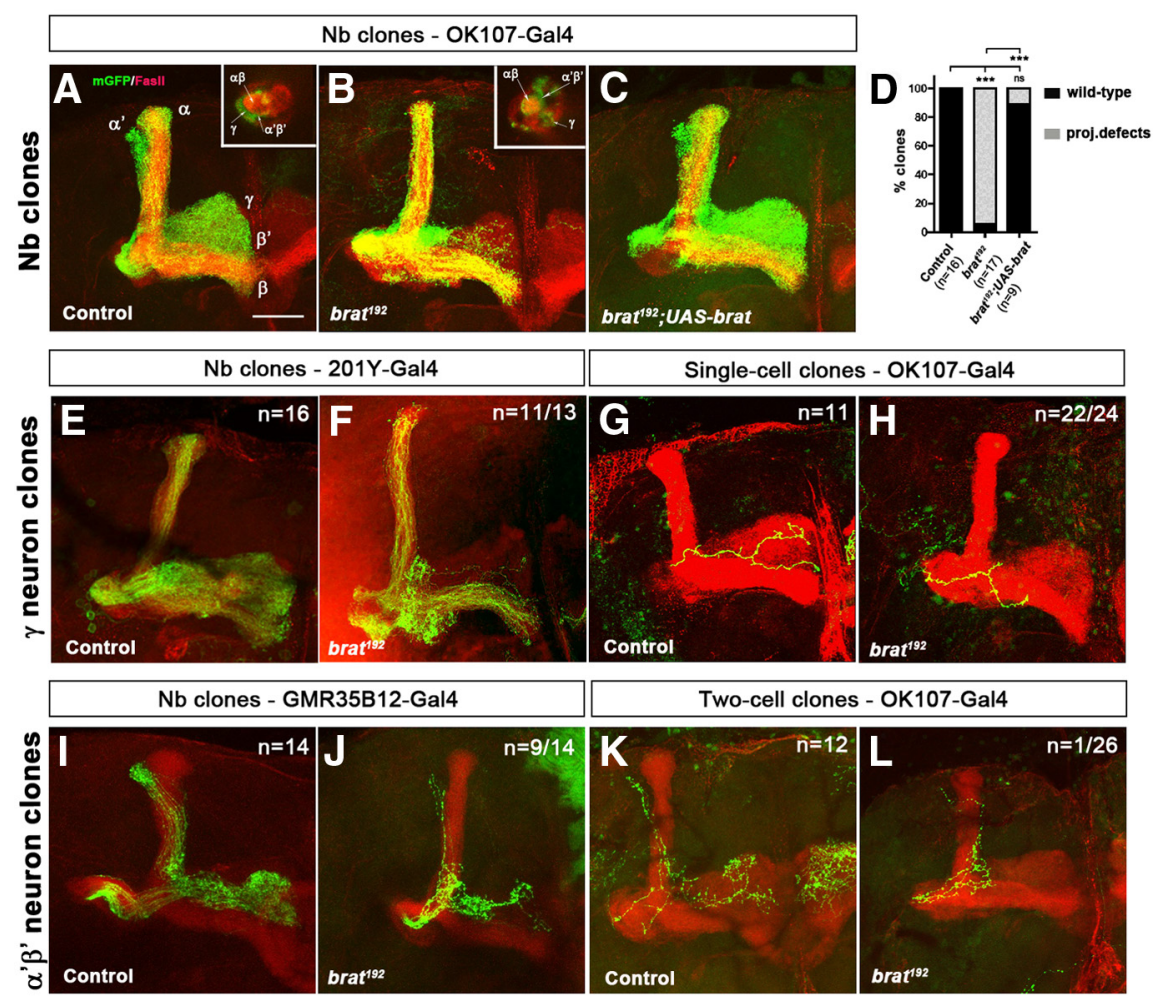

Figure 2. Brat is required cell autonomously for $M B \alpha^{\prime} \beta^{\prime}$ and $\gamma$ axon morphogenesis. $A, B$, Control $(\boldsymbol{A})$ and brat ${ }^{192}(\boldsymbol{B})$ adult MB neuroblast clones labeled with the 0K107-GAL4 driver. Insets, Cross sections of MB peduncles. C, Adult brat ${ }^{192}$ MB neuroblast clone expressing a wild-type copy of brat. D, Quantification of brat ${ }^{192}$ axonal defects in control, brat ${ }^{192}$, and brat ${ }^{192}$; UAS-brat MB neuroblast clones. ${ }^{* * *} p<0.001$ or n.s. (Fisher's exact test). $\boldsymbol{E}, \boldsymbol{F}$, Control $(\boldsymbol{E})$ and brat ${ }^{192}(\boldsymbol{F})$ adult neuroblast clones labeled with the 201Y-GAL4 driver. $\mathbf{G}, \boldsymbol{H}$, Control $(\boldsymbol{G})$ and brat ${ }^{192}(\boldsymbol{H})$ adult $\gamma$ single-cell clones labeled with the 0K107-GAL4 driver. I, J, Control (I) and brat ${ }^{192}(\boldsymbol{J})$ adult neuroblast clones labeled with the GMR35B12-GAL4 driver. $\boldsymbol{K}, \boldsymbol{L}$, Control $(\boldsymbol{K})$ and brat ${ }^{192}(\boldsymbol{L})$ adult $\alpha^{\prime} \boldsymbol{\beta}^{\prime}$ two-cell clones labeled with the 0K107-GAL4 driver. Green: mCD8::GFP. Red: Fasll. Scale bar, $20 \mu \mathrm{m}$. Numbers in the upper right corners indicate the numbers of scored clones that exhibited morphologies similar to those shown in the images. Complete genotypes: $(\boldsymbol{A}, \boldsymbol{G}, \boldsymbol{K})$ hsp-flp, UAS-mCD8::GFP; FRT40A tub-Gal80/FRT40A;;0K107-GAL4/+ (control); $(\boldsymbol{B}, \boldsymbol{H}, \boldsymbol{L})$ hsp-flp, UAS-mCD8::GFP; FRT40A tub-GAL80/FRT40A brat ${ }^{192 . ; 0 K 107-G A L 4 /+~}\left(\right.$ brat $\left.^{192}\right) ;($ (C) hsp-flp, UAS-mCD8::GFP; FRT40A tub-GAL80/ FRT40A brat $^{192}$; UAS-brat/+; 0K107-GAL4/+ (brat ${ }^{192}$; UAS-brat); (E) hsp-flp, UAS-mCD8::GFP; 201Y-GAL4 FRT40A tub-GAL80/ FRT40A (control); (F) hsp-flp, UAS-mCD8::GFP; 201Y-GAL4 FRT40A tub-GAL80/FRT40A brat ${ }^{192}$ (brat ${ }^{192}$ ); (I) hsp-flp, UAS-mCD8::GFP; FRT40A tub-GAL80/FRT40A; GMR35B12-GAL4/+ (control); (J) hsp-flp, UAS-mCD8::GFP; FRT40A tub-GAL80/ FRT40A brat $^{192} ;$ GMR35B12-GAL4/+ $\left(\right.$ brat $\left.^{192}\right)$.

promote axon stability, and that its NHL domain is necessary and sufficient for axon maintenance. These results reveal that Brat is a novel regulator of brain connectivity that controls the stability of neuronal circuits by modulating the levels of the conserved kinase Src.

\section{Materials and Methods}

Fly strains. Fly stocks used were as follows: UAS-brat RNAi lines (GD31333 and KK-105054 from the VDRC; HM05078 and HMS01121 from the Bloomington stock center); OK107-GAL4, GMR35B12-GAL4, tubGal80 ${ }^{\text {ts }}$, UAS-Src64B, mys ${ }^{1}, D f(3 L)$ Exel7208, rho1 ${ }^{72 F}, s q h^{A X 3}, D_{r o k}{ }^{1}$, Drok $^{2}$ (Bloomington stock center); Df(2R)ED2457, Src64B CPIo00567 (DGRC); FRT40A, brat ${ }^{192}$ (Betschinger et al., 2006); hs-FLP, UAS-mCD8::GFP; FRT40A tub-GAL80/Cy0;;OK107-GAL4 (Wu and Luo, 2006); hs-FLP, UAS-mCD8::GFP; 201Y-GAL4 FRT40A tubGAL80/Cy0 (Yaniv et al., 2012); UASp-Brat, UASp-Brat ${ }^{\text {G774D }}$, UASpBrat $^{\text {R837D }}$ (Harris et al., 2011); UAS-Brat ${ }^{\Delta 724-1037}(\Delta \mathrm{CT})$, UAS-Brat ${ }^{\Delta 63-}$ 721 (SNT Sonoda and Wharton, 2001); UAS-Wld (Hoopfer et al., 2006); $\operatorname{Src64B}^{K O}$ (O'Reilly et al., 2006); FRT82B pumilio ${ }^{E T 1}$ (Ye et al., 2004); nanos $^{B N}$ (Bier et al., 1989); nanos ${ }^{R C}$ (Lehmann and Nusslein-Volhard, 1991). Unless specified, KK-105054 line was used for brat RNAi. Flies were raised at $29^{\circ} \mathrm{C}$ for all RNAi experiments, and at $25^{\circ} \mathrm{C}$ for all MARCM experiments. For the $\operatorname{src} 64 \mathrm{~B}$ mild overexpression experiment, flies were raised at $18^{\circ} \mathrm{C}$. For the temperature-shift experiments, $0-24 \mathrm{~h}$ embryos were raised at $25^{\circ} \mathrm{C}$ (or $29^{\circ} \mathrm{C}$ ), shifted to $29^{\circ} \mathrm{C}$ ( or $25^{\circ} \mathrm{C}$ ) after $4 \mathrm{~d}$, $5 \mathrm{~d}, 6 \mathrm{~d}$, or $7 \mathrm{~d}$ of development, and dissected 3-4 d after eclosion.

Immunostaining and imaging. Brains of either sex were dissected in cold PBS, fixed, and immunostained as previously described (Wu and Luo, 2006). The following primary antibodies were used: mouse anti-FasciclinII 1D4 (1/15; Developmental Studies Hybridoma Bank, DSHB), mouse anti-Trio 9.4A (1/10; DSHB), rabbit anti-GFP A11122 (1/1000; Invitrogen), and rabbit anti-Brat (1/200; Betschinger et al., 2006). Secondary antibodies coupled to Cy 3 or Cy 5 were used (1/1000; Jackson ImmunoResearch). Immunofluorescent signals were collected with a Zeiss LSM 510 Meta confocal microscope using a $40 \times 1.3 \mathrm{NA}$ oil-immersion objective. Fluorescence intensities were measured on peduncle cross sections (Fig. $6 B-E$ ) or cell bodies (Fig. $6 F-I$ ), using the Fiji software (http://fiji.sc/Fiji). In Figure $6 D$, signal intensities were measured throughout entire peduncle sections. In Figure $6 E$, regions of interest were defined based on the FasciclinII staining. In both cases, background signals observed in the GFP channel (i.e., signal detected outside the peduncle) were subtracted. Recovered intensities were normalized to the control condition. In Figure 6, $F-I$, regions of interest were defined based on GFP staining, and intensities were normalized to control values.

In situ hybridizations. Fluorescent in situ hybridization experiments were performed as follows: brains were fixed for $1 \mathrm{~h}$ in $4 \%$ formaldehyde/PBS at $4^{\circ} \mathrm{C}$, washed in $\mathrm{PBS} / 0.1 \%$ Triton (PBT), gradually transferred into methanol, and stored at $-20^{\circ} \mathrm{C}$ for at least one night. Brains were then gradually transferred to PBT, incubated for $1 \mathrm{~h}$ in PBT/0.3\% $\mathrm{H}_{2} \mathrm{O}_{2}$, washed first in PBT, then in Hybe (formamide 50\%; SSC $5 \times$; Tween $0.1 \%$ )/PBT solution. Brains were subsequently incubated for $1 \mathrm{~h}$ at $55^{\circ} \mathrm{C}$ in hybridization buffer (formamide 50\%, SSC $5 \times$, Tween $0.1 \%$, heparin $50 \mu \mathrm{g} / \mathrm{ml}$; salmon sperm $200 \mu \mathrm{g} / \mathrm{ml}$, tRNA $50 \mu \mathrm{g} / \mathrm{ml}$ ) and hybridized overnight at $55^{\circ} \mathrm{C}$ in the same solution supplemented with DIG-labeled probes $(0.5 \mu \mathrm{g} / \mathrm{ml}$ final concentration). Samples were then washed $1 \mathrm{~h}$ in hybridization buffer at $55^{\circ} \mathrm{C}$ and extensively in PBT. Next, they were incubated for $1 \mathrm{~h}$ in blocking solution ( $1 \%$ blocking reagent/PBT; Roche \#11096176001) and overnight in the presence of HRP-coupled anti-DIG antibodies (1:500; Roche) and anti-GFP antibodies. After extensive washes in PBT, brains were incubated for $25 \mathrm{~min}$ in a Cy3 TSA plus solution (PerkinElmer), washed again extensively with PBT, and incubated with fluorescently coupled secondary antibodies. The $\operatorname{src} 64 B$ probes were cloned into the pSC-B vector using the StrataClone blunt PCR kit (Stratagene).

Cell sorting and $q R T-P C R$ analysis. qRT-PCR experiments were performed on total RNA extracted from FACS-purified larval MB neurons, largely as described previously (Berger et al., 2012). Briefly, control (UAS-mCD8::GFP/+; OK107-GAL4/+) or brat RNAi (UAS-mCD8:: GFP/UAS-brat-RNAi; OK107-GAL4/+) third instar larval brains were dissected in Rinaldini's solution (Ceron et al., 2006), enzymatically digested in papain and collagenase $\mathrm{I}(1 \mathrm{mg} / \mathrm{ml})$ for $60 \mathrm{~min}$, and then gently disrupted by pipetting in supplemented Schneider's medium. GFP ${ }^{+}$cells were isolated from the resulting cell suspension by FACS, and total RNA TRIzol-extracted. qRT-PCR experiments were performed as described previously (Berger et al., 2012), using the following primers: brat_fwd 
TCAGCGGTTGCGGCAGTAC/brat_rev GAT GCCCGAGTTGCCGCC; $s r c 64 B$ fwd GGGCA GTCTGCTGGACTTCT/src64B_rev CTCCGAT CAGCACATTACGG; RpS8_fwd CTTGGTGAA GAACAGCATCGTG/RpS8_rev GTCGTTCTC GTCCTCTTTCTGG. Six technical replicates from two independent biological samples were performed.

\section{Results}

\section{Brat is required for proper $\mathrm{MB}$} axon morphology

To identify new regulators of axon morphogenesis, we performed a selective RNAi screen using Drosophila MBs as a model system. Inducible UAS-RNAi constructs were expressed in all MB neurons using the OK107-GAL4 driver, and axons visualized with a membrane-tagged GFP (mCD8::GFP). Four independent UASRNAi lines, all targeting the brat gene, induced strong axonal morphology defects. In wild-type adults, $\mathrm{MB}$ axons exhibit specific branching patterns: $\alpha \beta$ and $\alpha^{\prime} \beta^{\prime}$ neuron axons bifurcate to produce a dorsal and a medial branch, while $\gamma$ neuron axons only project medially. As a result, two dorsal lobes $\left(\alpha^{\prime}\right.$ and $\alpha$ ) and three medial lobes $\left(\gamma, \beta^{\prime}\right.$, and $\left.\beta\right)$ can be observed (Fig. 1A). In contrast, adult brat RNAi MBs showed absence or truncation of dorsal lobes, as well as shortened medial lobes (Fig. $1 B, D, I$ ). These defects correlated with an accumulation of axonal material at the basis of MB lobes.

To test the efficiency of brat knockdown, we stained control and brat RNAi brains with anti-Brat antibodies (Betschinger et al., 2006). While a ubiquitous cytoplasmic signal was observed in the cell bodies of control larval and adult brains (Fig. $1 E, E^{\prime}$; data not shown), this signal was dramatically reduced in $\mathrm{MB}$ cell bodies upon brat RNAi (Fig. $1 F, F^{\prime}$; data not shown).

Brat was originally identified as a tumor suppressor, since brat mutations lead to neoplastic overgrowth characterized by enlargement of larval brain hemispheres (Arama et al., 2000). To test if brat regulates $\mathrm{MB}$ neuroblast proliferation, we first counted the number of MB neurons produced upon brat RNAi. Consistent with previous reports (Bello et al., 2006; Betschinger et al., 2006; Bowman et al., 2008), we did not find any significant difference in the number of adult MB neurons between control and brat RNAi conditions (data not shown). To then test if brat downregulation is associated with cell fate changes, we used two markers: FasciclinII (FasII), which is strongly expressed in $\alpha \beta$ neurons and weakly in $\gamma$ neurons, and Trio, which is expressed in $\alpha^{\prime} \beta^{\prime}$ and $\gamma$ neurons (Fig. $1 A, A^{\prime}, C, C^{\prime}$ ). Both markers are detected in brat RNAi MB lobes (Fig. $1 B, B^{\prime}, D, D^{\prime}$ ). As better visualized in optical sections across $\mathrm{MB}$ peduncles, brat RNAi axons segregate into typical concentric layers, with early born $\gamma$ axons in the outer layer, $\alpha^{\prime} \beta^{\prime}$ axons in the intermediate layer, and later born $\alpha \beta$ axons in the core layer (Fig. 1G,H). Thus, the three populations of $\mathrm{MB}$ neurons are correctly specified in brat RNAi context, but exhibit defective axonal projection patterns in adult.

\section{Brat cell autonomously regulates the morphology of $\gamma$ and $\boldsymbol{\alpha}^{\prime} \boldsymbol{\beta}^{\prime}$ axons}

As the development of the different populations of MB neurons is interdependent (Wang et al., 2002), we used the MARCM technique to generate brat mutant neuroblast $(\mathrm{Nb})$ clones in which the entire progeny of only one of the four $\mathrm{MB}$ neuroblasts is mutant (Lee et al., 1999). In control adult MB Nb clones, axonal branches of $\gamma, \alpha^{\prime} \beta^{\prime}$, and $\alpha \beta$ neurons project into distinct lobes (Fig. $2 A ; n=16)$. In brat ${ }^{192} \mathrm{Nb}$ clones $(n=17)$, in contrast, the majority of $\alpha^{\prime} \beta^{\prime}$ and $\gamma$ axonal branches failed to project into their respective lobes. Although both $\gamma$ and $\alpha^{\prime} \beta^{\prime}$ axons were detected in peduncle sections in this context (Fig. $2 B$, inset), they appeared to accumulate in the most proximal region of MB lobes (Fig. 2B). These defects were suppressed upon reexpression of a wild-type copy of Brat, confirming that brat 

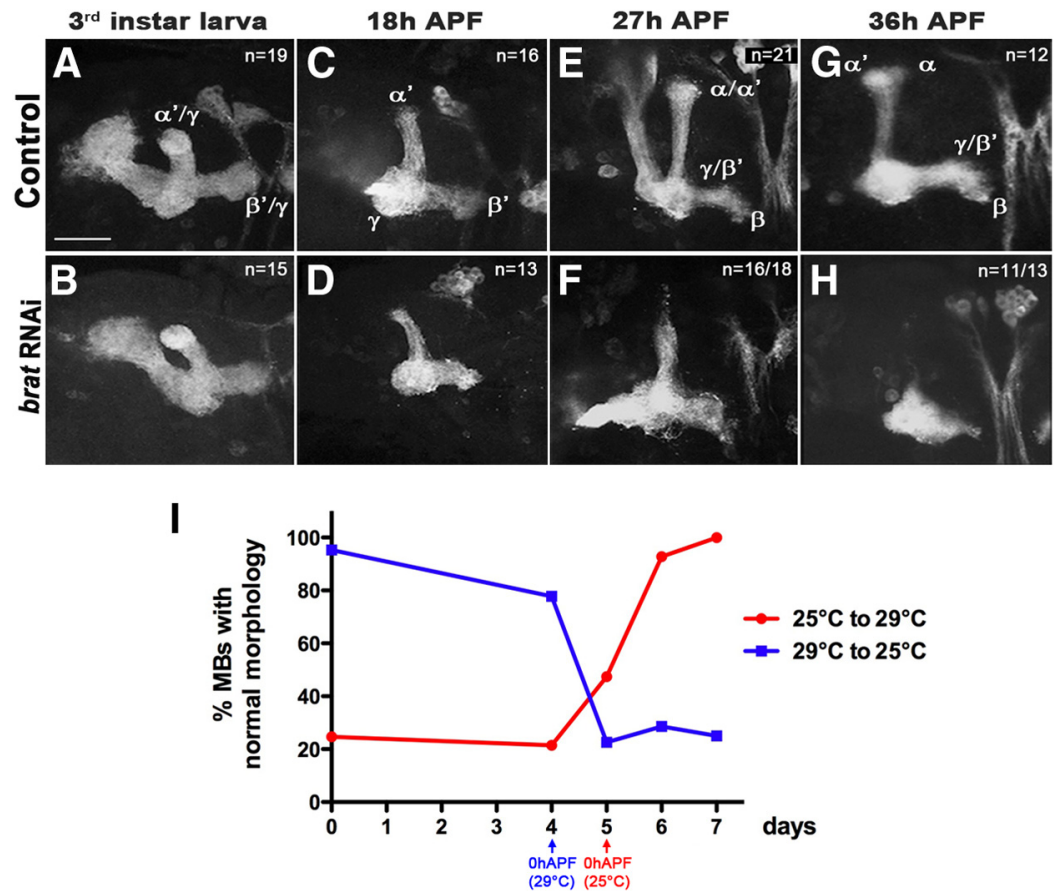

Figure 4. Brat prevents $M B$ axon retraction. MB lobe morphology at third instar larval stage $(\boldsymbol{A}, \boldsymbol{B}), 18 \mathrm{~h} \operatorname{APF}(\boldsymbol{C}, \boldsymbol{D}), 27 \mathrm{~h} \operatorname{APF}(\boldsymbol{E}$, $\boldsymbol{F})$, and $36 \mathrm{~h} \mathrm{APF}(\boldsymbol{G}, \boldsymbol{H})$ in control (upper line) and brat RNAi (lower line) conditions. Numbers in the upper right corners indicate the numbers of scored MBs that exhibited morphologies similar to those shown in the images. Signal in $\boldsymbol{A}-\boldsymbol{H}$ : $\mathrm{mCD8}: . \mathrm{GFP}$. Scale bar, 20 $\mu \mathrm{m}$. Complete genotype:UAS-mCD8::GFP/+;;0K107-GAL4/+ (control);UAS-mCD8::GFP/UAS-brat-RNAi;0K107-GAL4/+ (brat RNAi). $I$, Temperature-shift experiments. Graph showing the percentages of MBs with wild-type morphology as a function of temperature-shift timing. At $29^{\circ} \mathrm{C}$ (restrictive temperature), Gal $80^{\text {ts }}$ is not active, enabling expression of the brat RNAi transgene. At $25^{\circ} \mathrm{C}$ (permissive temperature), in contrast, Gal $80^{\text {ts }}$ is active, preventing expression of the brat RNAi transgene. The tempora resolution of these experiments is $24 \mathrm{~h}$ (see Materials and Methods). Note that developmental timing is different at 25 and $29^{\circ} \mathrm{C}$ while pupariation occurs $\sim 5 \mathrm{~d}$ after egg laying at $25^{\circ} \mathrm{C}$, it occurs $\sim 4 \mathrm{~d}$ after egg laying at $29^{\circ} \mathrm{C}$. Complete genotype: UAS-mCD8::GFP/UAS-brat-RNAi; tub-Gal80 ${ }^{\text {ts }} /+; 0$ K107-GAL4/+
A

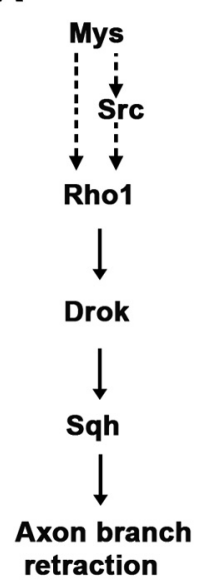

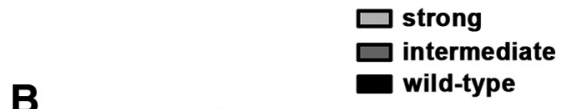

B

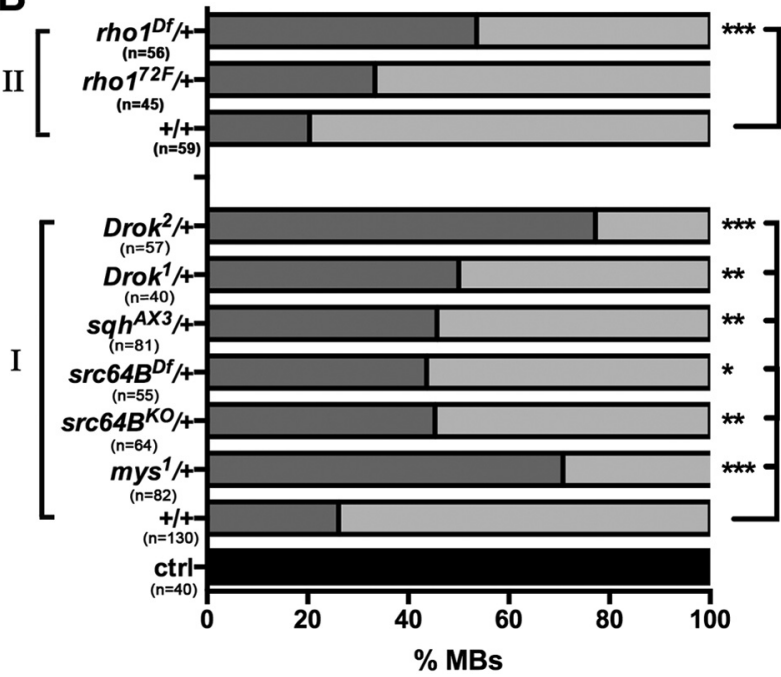

Figure 5. brat genetically interacts with components of a conserved rho-dependent signaling pathway. $\boldsymbol{A}$, Rho-dependent genetic pathway controlling axon retraction. Dashed arrows indicate that Mys and Src are not directly regulating Rho1. Adapted from Billuart et al., 2001. B, Percentages of MBs exhibiting wild-type, intermediate, and strong axonal defects (as defined in Fig. 1/), after removal of one copy of Rho-signaling components in a brat RNAi context (UAS-brat-RNAi/+; 0K107-GAL4/+). For technical reasons, KK-105054 brat RNAi line was used for group I experiments; GD-31333 line was used for group II experiments. Note that the proportion of strong phenotypes observed upon brat RNAi is lower in the absence of UAS-mCD8::GFP transgene (compare with Fig. 1/). Numbers correspond to the total number of scored MBs. Statistical comparison to the brat RNAi control: ${ }^{*} p<0.05$; ${ }^{* *} p<0.01$, and ${ }^{* * *} p<0.001$ (Fisher's exact test). cell autonomously controls $\alpha^{\prime} \beta^{\prime}$ and $\gamma$ axonal projection patterns (Fig. $2 C, D$ ).

Strikingly, brat ${ }^{192}$ mutant $\alpha \beta$ neurons showed normal dorsal and medial branches in this analysis (Fig. 2B), revealing that Brat regulates $\mathrm{MB}$ axon morphology in a population-specific manner. To better visualize the different populations of $\mathrm{MB}$ neurons in our MARCM analysis, we used two complementary GAL4 drivers, one expressed in $\gamma$ neurons and core $\alpha \beta$ neurons (201Y-GAL4), the other in $\alpha^{\prime} \beta^{\prime}$ neurons (GMR35B12-GAL4). As shown in Figure 2, E, F,I, and $J$, axonal material accumulating proximally was observed when using either 201Y-GAL4 or GMR35B12GAL4 to label brat ${ }^{192} \mathrm{Nb}$ clones $(n=13$ and 14 , respectively), indicating that both $\gamma$ and $\alpha^{\prime} \beta^{\prime}$ neurons mutant for brat exhibit defective axon elongation.

To visualize the morphology of individual axons, we then generated singlecell clones using a previously established protocol (Lee et al., 1999). Single-cell $\gamma$ neuron clones were induced at early larval stages and observed in adults. While adult $\gamma$ axons normally exhibit axonal branches reaching the tip of MB medial lobe, brat $^{192}$ $\gamma$ neurons showed markedly shorter axonal branches that typically failed to extend beyond the proximal half of the medial lobe (Fig. 2G,H). In parallel, twocell $\alpha^{\prime} \beta^{\prime}$ neuron clones were induced in late larval stages and observed in adults. brat $^{192} \alpha^{\prime} \beta^{\prime}$ neurons exhibiting axon projection defects could be observed (Fig. $2 L)$, although at a low frequency $(1 / 26)$. Such a low penetrance was not observed when generating $\alpha^{\prime} \beta^{\prime}$ neuroblast mutant clones (Fig. 2J), and thus likely results from the perdurance of wild-type Brat proteins in two-cell clones induced late during development (Zhu et al., 2005).

Altogether, these results demonstrate that Brat regulates the morphology of specific subpopulations of $\mathrm{MB}$ axons: brat function is required cell autonomously in $\gamma$ and $\alpha^{\prime} \beta^{\prime}$ MB neurons, but not in $\alpha \beta$ neurons.

Brat is required for the maintenance of MB axon branches

brat mutant adult phenotypes can be interpreted either as a failure of $\mathrm{MB}$ axons to elongate or as defective axon maintenance. To distinguish between these two possibilities, we first analyzed the morphology of MB lobes at larval and early pupal stages. At the end of the third instar larval stage, wild-type MBs are composed of $\gamma$ and $\alpha^{\prime} \beta^{\prime}$ neurons, both projecting axonal branches into a dorsal and a medial lobe (Fig. $3 A$ ). At this stage, no morpho- 
A

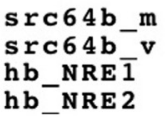

s rc6 6 b_m

hb NRE 2
Pum binding motif

TTAGCGTAGTTGA TGAATTTTGTATATAAACTT

-TTAGCGTAGTTGATGAATTTTGTATATATACTT

CATATAATCGTTGTCCAG-AATTGTATATATTCG-

CATTATTTGTTGTCGAA-AATTGTACATAAGC--
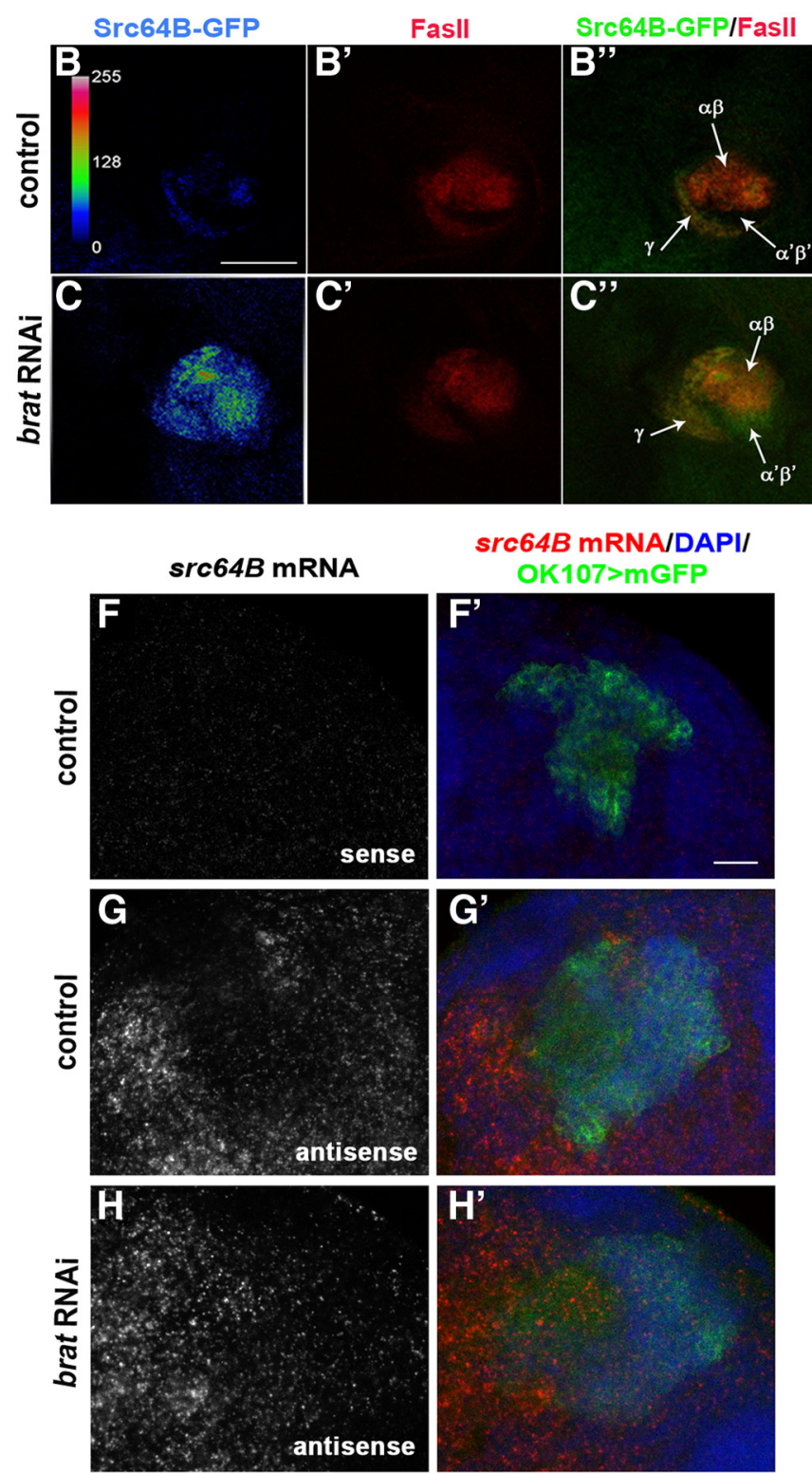

src64B mRNA/DAPI/
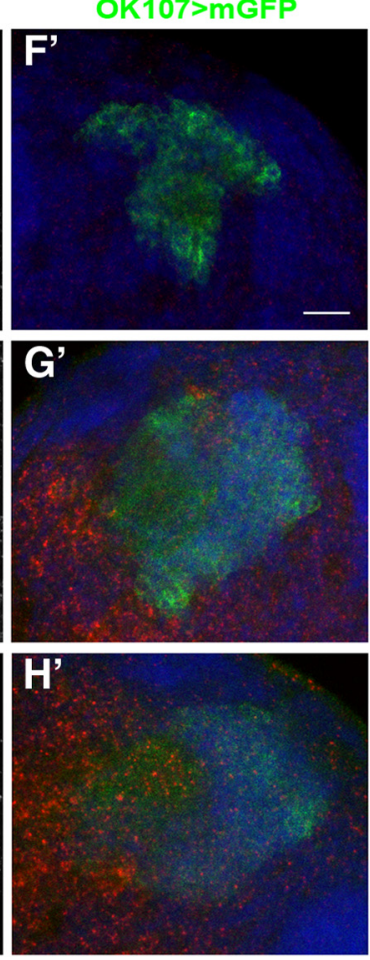

D

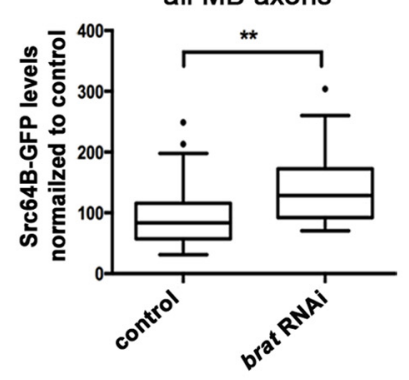

E

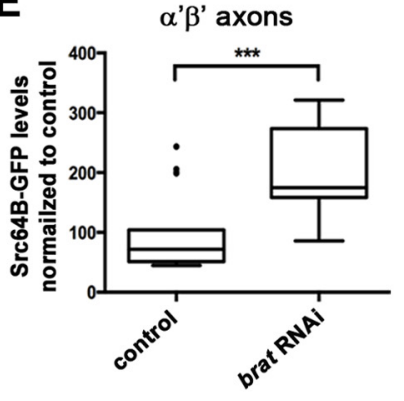

I
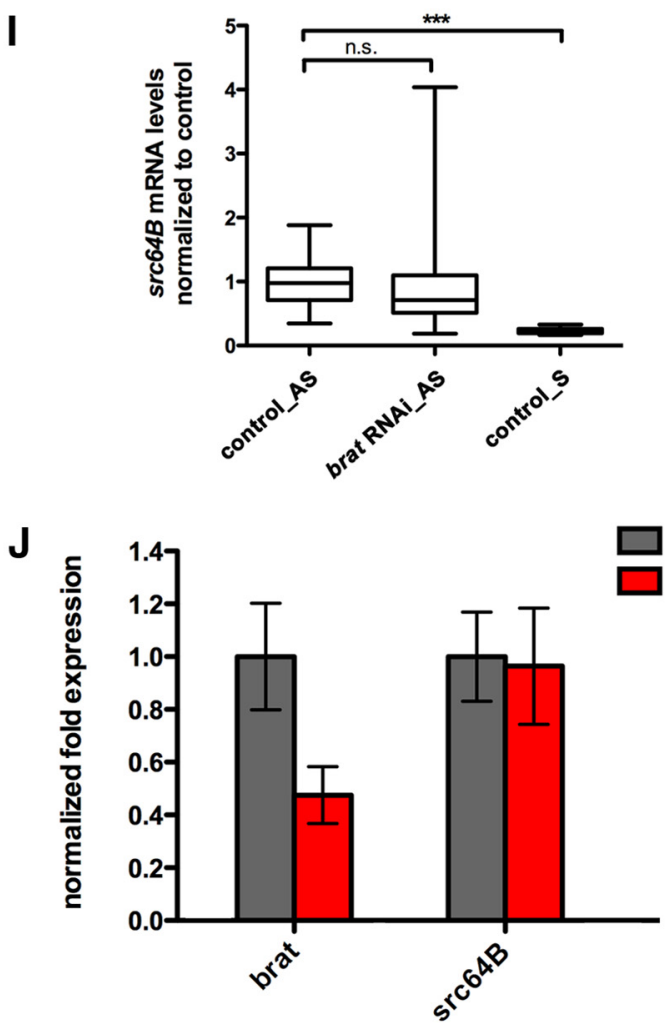

control

brat_RNAi

Figure 6. Brat post-transcriptionally represses src64B expression. $A$, Alignment between hunchback ( $h b$ ) NREs and the NRE-like sequences found in the $3^{\prime} U T R$ of Drosophila melanogaster ( $m$ ) and virilis (v) src64B mRNA. $\boldsymbol{B}-\boldsymbol{C}^{\prime \prime}$, Cross sections of control $\left(\boldsymbol{B}-\boldsymbol{B}^{\prime \prime}\right)$ and brat RNAi $\left(\boldsymbol{C}-\boldsymbol{C}^{\prime \prime}\right)$ adult MB peduncles expressing Src64B::GFP protein-trap fusions and stained with anti-GFP (green in the overlay) and anti-Fasll antibodies (red in the overlay). Note that Src64B-GFP signal intensities in $\boldsymbol{B}$ and $\boldsymbol{C}$ were color coded using the ImageJ Rainbow RGB look-up table (see intensity level scale in $\boldsymbol{B}$ ). Scale bar, $10 \mu \mathrm{m}$. $\boldsymbol{D}, \boldsymbol{E}$, Quantification of Src64B::GFP signal intensities in control and brat RNAi contexts for all MB axons $(\boldsymbol{D})$ or $\alpha^{\prime} \beta^{\prime}$ axons only $(\boldsymbol{E}) ; n=20$ for each genotype. Statistical comparison to the control::** $p<0.001$; ${ }^{* *} p<$ 0.01 (Mann-Whitney tests). $\boldsymbol{F}-\boldsymbol{H}$, Cell bodies of control $\left(\boldsymbol{F}-\boldsymbol{G}^{\prime}\right)$ and brat RNAi $\left(\boldsymbol{H}, \boldsymbol{H}^{\prime}\right)$ larval MB neurons hybridized with sense $\left(\boldsymbol{F}, \boldsymbol{F}^{\prime}\right)$ or antisense $\left(\boldsymbol{G}-\boldsymbol{H}^{\prime}\right)$ src64B probes, and labeled with anti-GFP antibodies (green in the overlay) and DAPI (blue in the overlay). The RNA signal is shown in white in $\boldsymbol{F}-\boldsymbol{H}$ and in red in $\boldsymbol{F}^{\prime}-\boldsymbol{H}^{\prime}$. Scalebar, $20 \mu \mathrm{m}$. $\boldsymbol{I}$, Quantification of src64B mRNAlevels in control and brat RNAicontexts. Signal intensities were measured within $\mathrm{GFP}^{+}$cells and normalized to the control. AS, antisense probes; $S$, sense probes; $n=28$ and 30 for control brains hybridized with sense and antisense probes, respectively, and $n=40$ for brat RNAi brains hybridized with antisense probes. Statistical comparison to the control: ***p $<0.001$ or n.s. (Mann-Whitney tests).J, Normalized expression of brat (left) and src64B (right) mRNA in control (dark gray) and brat RNAi (red) MB neurons. qRT-PCR was performed on RNA extracted from FACS-sorted larval neurons (see Materials and Methods). Error bars indicate STD. Complete genotypes: UAS-mCD8::GFP/+;0K107-GAL4/+ (control) and UAS-mCD8::GFP/UAS-brat-RNAi;;OK107-GAL4/+ (brat RNAi).

logical defects were observed in brat ${ }^{192} \mathrm{Nb}$ clones (Fig. $3 B ; n=$ 11 ) or brat RNAi (Fig. $4 A, B ; n=15$ ) conditions, suggesting that brat is not required for the initial growth of early born $\mathrm{MB}$ neuron axons. During early metamorphosis, the larval axonal branches of $\gamma$ axons undergo controlled pruning, a process that eliminates both the dorsal and the medial terminal branches and is completed $18 \mathrm{~h}$ after puparium formation (APF; Lee et al., 1999; Watts et al., 2003). This process is specific for $\gamma$ neurons, as $\alpha^{\prime} \beta^{\prime}$ 

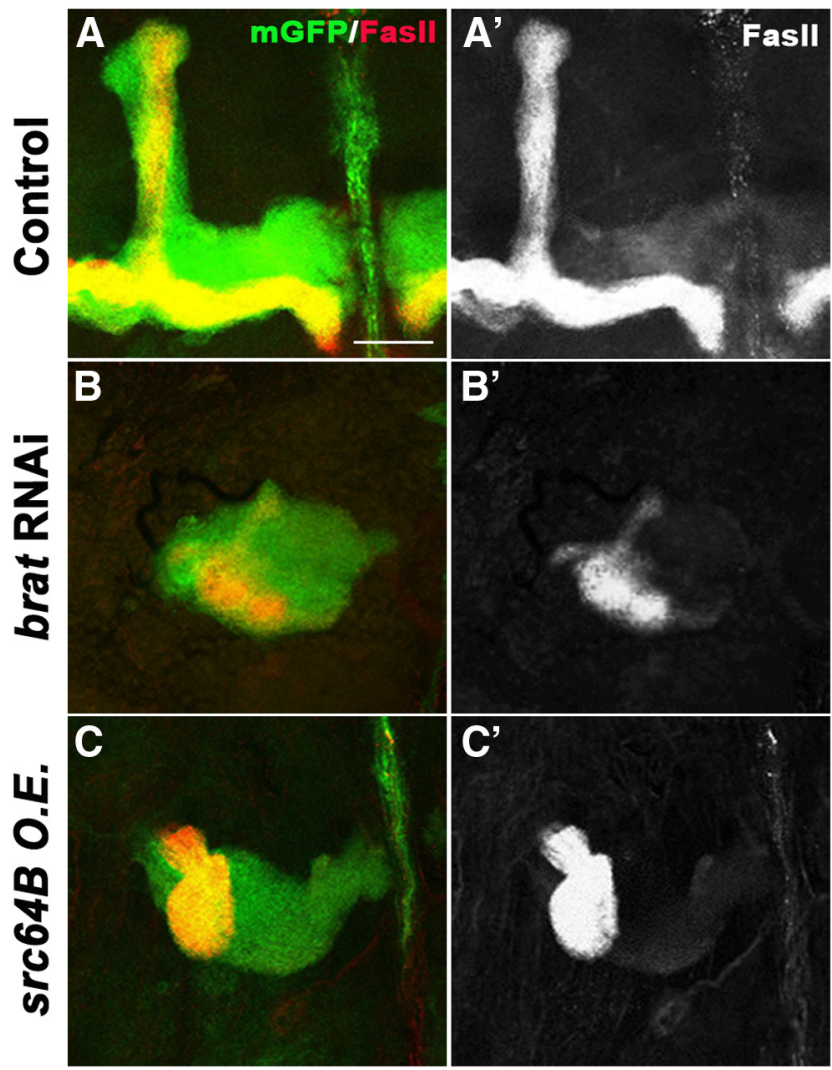

Figure 7. src64b overexpression phenocopies brat downregulation. Adult MB lobes from control $\left(\boldsymbol{A}, \boldsymbol{A}^{\prime}\right)$, brat RNAi $\left(\boldsymbol{B}, \boldsymbol{B}^{\prime}\right)$, and src64B-overexpressing $\left(\boldsymbol{C}, \boldsymbol{C}^{\prime}\right)$ brains. Green in $\boldsymbol{A}-\boldsymbol{C}$ : OK107-GAL4-driven mCD8::GFP. Red in $\boldsymbol{A}-\boldsymbol{C}$ and white in $\boldsymbol{A}^{\prime}-\boldsymbol{C}^{\prime}$ : Fasll. Scale bar, $20 \mu \mathrm{m}$. Complete genotypes: UAS-mCD8::GFP/+;:0K107-GAL4/+ (control); UAS-mCD8::GFP/UASbrat-RNAi;;0K107-GAL4/+ (brat RNAi), and UAS-mCD8::GFP/+; UAS-scr64B/+; 0K107GAL4/+ (src64B overexpression)

axonal branches are maintained throughout metamorphosis. As shown in Figure 3, C and D, brat ${ }^{192} \mathrm{Nb}$ clones exhibited a morphology similar to that of wild-type Nb clones at $18 \mathrm{~h} \mathrm{APF}(n=12$ and 10 for wild-type and $b r a t^{192} \mathrm{NB}$ clones, respectively). Larval $\gamma$ axonal branches were pruned normally, and $\alpha^{\prime} \beta^{\prime}$ neurons with extended dorsal and medial branches were observed. Shortly after pruning, $\mathrm{MB} \gamma$ axons initiate a regrowth program characterized by the extension of medial adult-specific projections (Yaniv et al., 2012). At $24-26$ h APF, brat ${ }^{192} \gamma$ axons had regrown similarly to wild-type axons (Fig. 3 E, F; $n=13$ and 11 for wild-type and $b r a t^{192}$ NB clones, respectively), indicating that brat phenotypes do not result from a failure to initiate the $\gamma$ axon regrowth program. Altogether, these results indicate that brat is not required for larval and early pupal axon morphogenesis.

To determine the stage at which axonal defects start being observed, we analyzed the morphology of brat RNAi MB lobes across metamorphosis. Consistent with our MARCM analysis, brat RNAi lobes were indistinguishable from wild-type at larval stage and at $18 \mathrm{~h} \mathrm{APF} \mathrm{(Fig.} \mathrm{4C,D;} n=19$ and 15 for wild-type and brat RNAi larval MBs; $n=16$ and 13 for wild-type and brat RNAi $18 \mathrm{~h} \mathrm{APF} \mathrm{MBs).} \mathrm{At} 27 \mathrm{~h} \mathrm{APF}$, however, brat RNAi MBs lacked the most distal part of their dorsal lobe (Fig. $4 E, F ; n=18$ ). At $36 \mathrm{~h}$ APF, brat RNAi MBs lacked their dorsal lobes, and exhibited severely reduced medial lobes (Fig. $4 G, H ; n=13$ ). Notably, the distal to proximal progressive loss of $\mathrm{MB}$ lobes correlated with an accumulation of axonal material at the basis of the peduncle, suggesting that brat mutant axons undergo retraction rather than degeneration. To validate this hypothesis, we expressed in a brat RNAi context the Wallerian degeneration slow $\left(\mathrm{Wld}^{\mathrm{s}}\right)$ protein, which has been shown in different contexts to inhibit neurite degeneration (Luo and O'Leary, 2005; Hoopfer et al., 2006; Schoenmann et al., 2010). OK107-GAL4-driven expression of the $\mathrm{Wld}^{\mathrm{s}}$ protein did not rescue the brat RNAi phenotypes (data not shown; $n=60$ ), confirming that brat mutant axons are not undergoing Wallerian degeneration.

To determine when the function of brat is required during development, we used the TARGET system to temporally control the expression of the UAS-brat RNAi transgene (McGuire et al., 2004). Two complementary temperature-shift experiments were performed. In the first one, flies were raised at $25^{\circ} \mathrm{C}$ (no expression of brat RNAi) and shifted to $29^{\circ} \mathrm{C}$ (expression of brat RNAi) at different developmental time points (Fig. $4 I$, red curve). In the second one, flies were raised at $29^{\circ} \mathrm{C}$ and shifted to $25^{\circ} \mathrm{C}$ (Fig. $4 \mathrm{I}$, blue curve). These experiments revealed that the function of Brat is necessary in a restricted window of time, at pupariation.

Thus, brat is neither required for MB axon initial growth, nor for the remodeling of $\mathrm{MB} \gamma$ neurons. Rather, its function is required at the onset of metamorphosis to prevent the retraction of $\gamma$ and $\alpha^{\prime} \beta^{\prime}$ axons.

\section{Brat regulates a Rho-dependent axon retraction pathway by} repressing src $64 \mathrm{~B}$ post transcriptionally

Maintenance of $\mathrm{MB}$ axon lobes is an active process that requires inhibition of a Rho-dependent axon retraction pathway (Billuart et al., 2001). Indeed, expression of a constitutively active form of Rhol or of Drosophila Rho-associated kinase (Drok) leads to truncated dorsal lobes, a phenotype that can be partially suppressed by removing one copy of spaghetti squash (sqh), which encodes the Drosophila myosin regulatory light chain (Billuart et al., 2001). src64B, the Drosophila src homolog, and myospheroid ( $m y s$ ), the $\beta$ PS integrin encoding gene, have both been proposed to act upstream of these components to prevent excessive axon extension (Fig. 5A) (Billuart et al., 2001). To test whether brat genetically interacts with components of this retraction pathway, we removed one copy of mys, src64B, rho1, sqh, or Drok in a brat RNAi context. As shown in Figure $5 B$, this significantly suppressed the brat mutant phenotypes, suggesting that Brat acts as a negative regulator of the Rho-dependent axon retraction pathway.

In early embryo, Brat represses the translation of hunchback mRNA by forming a tripartite complex containing Nanos (Nos) and Pumilio (Pum; Sonoda and Wharton, 2001). Although it had initially been proposed that the RNA binding protein Pum serves as a platform to recruit Brat and Nos to target RNAs (Sonoda and Wharton, 2001), it was recently demonstrated that Brat directly binds to the Nanos Response element (NRE) of hunchback 3'UTR (Loedige et al., 2014). Notably, Brat recognizes a sequence (BoxA motif) that flanks the Pum binding site (Fig. 6A). Furthermore, the recruitment of Brat is facilitated by Pum binding within the hunchback NRE (Loedige et al., 2014). To identify potential Brat targets, we analyzed the sequence of mRNAs encoding positive regulators of the previously described Rhodependent pathway. src64B mRNA was the only transcript containing in its $3^{\prime}$ UTR a BoxA-like sequence flanked by a canonical UGUA(A/U/C)AUA Pum-binding motif (Fig. 6A; Gerber et al., 2006). This sequence is conserved throughout evolution and closely matches that of hunchback NREs.

To test if $\operatorname{src} 64 B$ is a target of Brat in vivo in $\mathrm{MB}$ neurons, we used a protein trap line in which Src64B::GFP fusions are expressed from the endogenous locus (Knowles-Barley et al., 
2010). In control adult brains, low levels of Src64B::GFP are detected in $\gamma$ and $\alpha \beta$ $\mathrm{MB}$ axons (Fig. $6 B-B^{\prime \prime}$, cross section of the peduncle). Strikingly, a significant increase in Src64::GFP levels was observed in $\mathrm{MB}$ axons upon brat inactivation (Fig. $\left.6 C-C^{\prime \prime}, D\right)$. This increase was particularly clear in $\alpha^{\prime} \beta^{\prime}$ axons where Src64B::GFP was not detected in control MBs (Fig. $6 E$ ). To test if the observed increase in Src64B protein levels was associated with increased levels of $\operatorname{src} 64 \mathrm{~B} \mathrm{mRNA}$, we performed in situ hybridizations on brat RNAi and control brains. No significant change in $\operatorname{src} 64 B$ mRNA levels was observed upon brat inactivation in $\mathrm{MB}$ neurons (Fig. $6 F-I$ ). To more quantitatively estimate the levels of $\operatorname{src} 64 \mathrm{~B}$ mRNA, we isolated neuronal cells expressing GFP under the control of the OK107-GAL4 driver, and performed qRT-PCR on RNA extracted from $\mathrm{GFP}^{+}$cells. Similar amounts of $\operatorname{src} 64 \mathrm{~B}$ mRNA were found in control and brat RNAi brains (Fig. 6J), indicating that Brat regulate $s r c 64 B$ mRNA at the post-transcriptional level.

Finally, to test if the elevated levels of Src64B were responsible for the axon retraction defects observed upon brat inactivation, we overexpressed scr64B in $\mathrm{MB}$ neurons using OK107-GAL4. As shown in Figure $7, A-C$, mild overexpression of $\operatorname{src} 64 B$ phenocopied the brat RNAi defects and induced a shrinkage of $\mathrm{MB}$ lobes $(n=18)$.

Altogether, these results indicate that Brat prevents $\mathrm{MB}$ axon retraction by repressing the translation of $\operatorname{src} 64 B$.

Brat controls $\mathrm{MB}$ axon maintenance independently of the Nanos/Pumilio complex and of $\mathrm{d} 4 \mathrm{EHP}$

In embryo and larval peripheral nervous systems, Brat cooperates with Nos and Pum to repress the translation of target mRNAs (Sonoda and Wharton, 2001; Cho et al., 2006; Muraro et al., 2008; Olesnicky et al., 2012). Therefore, we investigated whether Brat is acting together with Nos and Pum to inhibit axon retraction. First, we tried to phenocopy brat mutant phenotypes by inactivating nos or pum expression. None of the nos $(n=3)$ or pum $(n=3)$ RNAi transgenic lines we tested disrupted axon morphology when combined with OK107-GAL4 (data not shown). Furthermore, $\operatorname{nos}^{R C} /$ nos $^{B N} \mathrm{mu}-$ tant flies exhibited normal MB lobes ( $n=25$; Bier et al., 1989; Lehmann and Nusslein-Volhard, 1991), and pum ${ }^{E T 1}$ mutant $\gamma$ neurons (Forbes and Lehmann, 1998) were indistinguishable from control neurons when analyzed using the MARCM technique ( $n=21$; data not shown). Second, we tried to rescue brat phenotypes by expressing a form of Brat that cannot associate with the Pum/Nos/hunchback NRE complex (Brat ${ }^{\text {G774D }}$; Sonoda and Wharton, 2001; Harris et al., 2011). Although the G774D mutation was initially thought to disrupt a putative Pum-Brat brat $^{\Delta \mathrm{NT}}$; rescue).

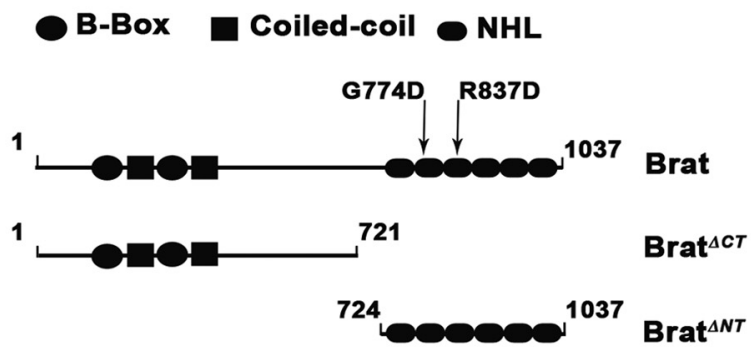

wild-type proj. defects
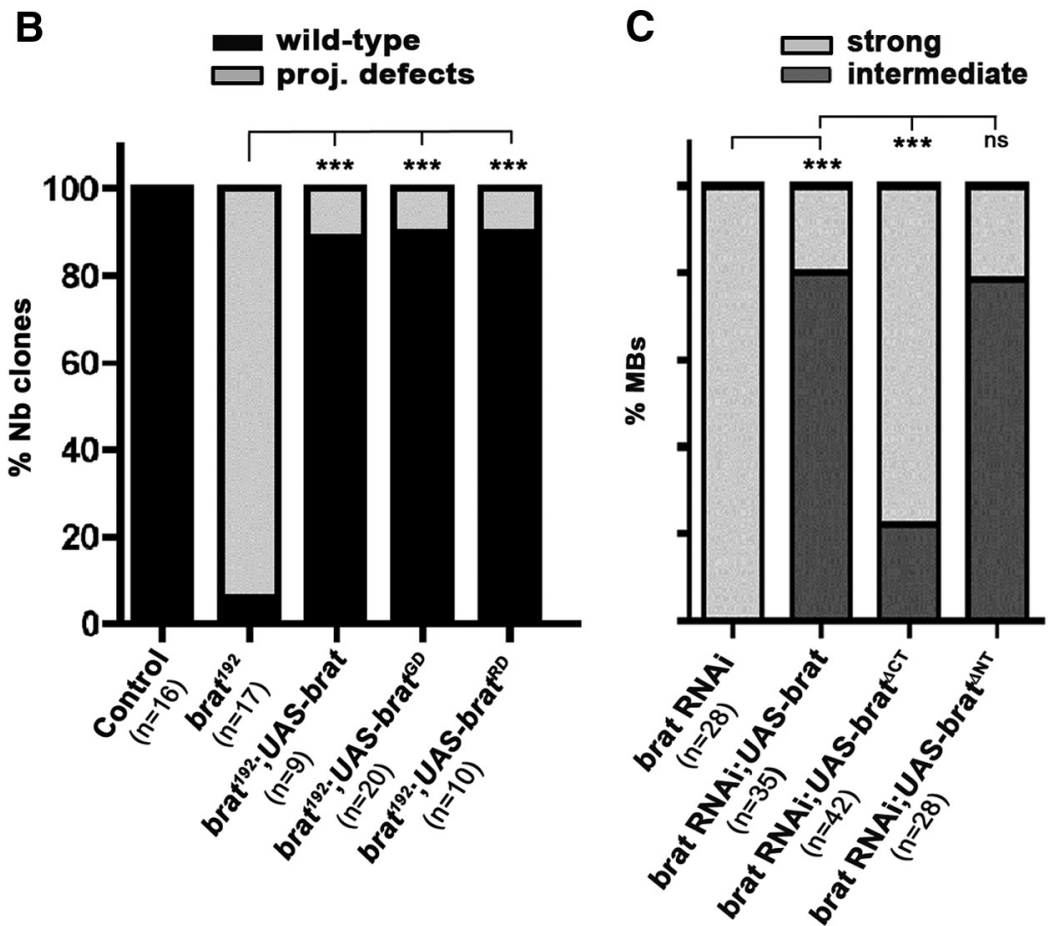

Figure 8. Brat acts independently of the Nanos/Pumilio complex and of d4EHP. A, Schematic representation of Brat protein domains. Top, Full-length protein with the G774D and R837D point mutations indicated with arrows. Bottom, Brat ${ }^{\Delta C T}$ and Brat ${ }^{\Delta \mathrm{NT}}$ truncated versions. $B$, Percentages of axonal defects in MB neuroblast clones from control, brat ${ }^{192}$, and brat $^{192}$; brat $^{\text {tht }}$, (Fisher's exact test). Numbers correspond to the total number of scored clones. C, Percentages of MBs with intermediate or strong phenotypes (as defined in Fig. 1/) in brat RNAi and Brat ${ }^{\Delta \mathrm{CT}}$ or Brat ${ }^{\Delta \mathrm{NT}}$ rescue contexts. Numbers correspond to the total number (brat ${ }^{192}$ ); hsp-flp, UAS-mCD8::GFP; FRT40A tub-GAL80/FRT40A brat ${ }^{192}$; UAS-brat or brat ${ }^{6774 D}$ or brat $^{\text {R837D } /+; 0 K 107-G A L 4 /+~}$ UAS-mCD8::GFP/UAS-brat or brat ${ }^{\Delta C T}$ or brat ${ }^{\Delta \mathrm{NT}}$; UAS-brat-RNAi/+; 0K107-GAL4/+ (brat RNAi; UAS-brat or brat ${ }^{\Delta C \mathrm{~T}}$ or

interaction (Sonoda and Wharton, 2001), it was recently proposed to rather prevent the Pum-enhanced association of Brat to RNA (Loedige et al., 2014). Strikingly, expression of Brat $^{\text {G774D }}$ was able to rescue brat $^{192} \mathrm{Nb}$ clone phenotype (Fig. $8 A, B)$. Altogether, these results indicate that Brat acts independently of Nos and Pum to control MB axon maintenance.

Previous work has shown that Brat represses the translation of hunchback mRNA in embryo by interacting with d4EHP, an eIF4Elike cap binding protein (Cho et al., 2006). As shown in Figure $8 B$, however, a mutant form of Brat protein that cannot interact with d4EHP (Brat ${ }^{\text {R837D; }}$; Cho et al., 2006; Harris et al., 2011) rescued brat $^{192} \mathrm{Nb}$ clone phenotypes similarly to wild-type Brat protein, further indicating that Brat function in $\mathrm{MB}$ neurons is independent of its previously described partners. 
Drosophila Brat contains conserved domains characteristic of members of the TRIM-NHL family: two B-Box motifs and Coiled-coil regions at the $\mathrm{N}$ terminus, and an NHL domain at the $\mathrm{C}$ terminus (Fig. 8A). To determine which domain of Brat is important for axon maintenance in vivo, we expressed in a brat RNAi context a $\Delta \mathrm{C}$-ter form of Brat lacking the NHL domain, or a $\Delta \mathrm{N}$-ter form of Brat lacking both B-Box and Coiled-coil domains. Expression of Brat ${ }^{\Delta \mathrm{NT}}$, but not Brat ${ }^{\Delta \mathrm{CT}}$, was able to rescue brat phenotypes (Fig. $8 C$ ), revealing that Brat NHL domain is both necessary and sufficient in vivo for axon maintenance.

\section{Discussion}

In this article, we demonstrated that the conserved TRIM-NHL protein Brat is a novel regulator of neuronal structure maintenance that post-transcriptionally tunes the levels of the kinase Src, an upstream regulator of a conserved Rho signaling pathway preventing axon retraction.

\section{Brat post-transcriptionally represses $\operatorname{src} 64 \mathrm{~B}$ expression}

In Drosophila early embryo and larval peripheral nervous systems, Brat cooperates with Nanos, Pumilio, and d4EHP to repress the translation of target mRNAs (Sonoda and Wharton, 2001; Cho et al., 2006; Muraro et al., 2008; Olesnicky et al., 2012). We have shown that, in centrally located MB neurons, Brat promotes axon maintenance by repressing the translation of $\operatorname{src} 64 \mathrm{~B}$ mRNA. Surprisingly, our genetic analysis has revealed that Brat prevents axon retraction independently of its previously described partners. Although src64B mRNA contains a Pumbinding motif, its regulation by Brat is thus likely independent of Pum activity. This is consistent with recent work indicating that translation repression by Brat can occur independently of Pum in Drosophila S2 cells, and that Brat binds RNA independently of Pum, via its NHL domain (Loedige et al., 2014). Notably, similar conclusions were drawn with Brat mammalian ortholog TRIM71 (Loedige et al., 2013). This, together with modeling analyses (Loedige et al., 2014) and large-scale mRNA interactome studies (Kwon et al., 2013) led to an emerging model in which TRIMNHL proteins are direct RNA binding proteins that recognize target mRNAs via their NHL domain.

Here, we have shown that Brat NHL domain is both necessary and sufficient for $\mathrm{MB}$ axon maintenance in vivo, and have identified src64B mRNA as a target of Brat in MB neurons. How Brat represses $\operatorname{src} 64 B$ at the molecular level remains to be addressed. Three closely related members of the TRIM-NHL family of proteins (Drosophila Mei-P26 and mammalian TRIM-32 and TRIM71) have been shown to physically interact with the RISC component Ago1 or Ago2 (Neumüller et al., 2008; Schwamborn et al., 2009; Wulczyn et al., 2011; Chang et al., 2012). Furthermore, these proteins regulate microRNA activity, either positively (Schwamborn et al., 2009; Wulczyn et al., 2011; Chang et al., 2012) or negatively (Neumüller et al., 2008). Although Brat coimmunoprecipitates with Ago 1 in embryo extracts (Neumüller et al., 2008), a role of Brat in the regulation of the microRNA machinery has not been demonstrated so far. In MBs, the observed brat mutant phenotype does not appear to result from a downregulation of microRNA levels and/or activity, as no axon retraction defects were detected in neurons mutant for core components of the microRNA pathway (data not shown). In addition, brat mutant phenotypes could not be suppressed by removing one dose of miRNA pathway components, further supporting a miRNA-independent function of Brat in this system.

\section{Brat, a novel regulator of axon maintenance}

Our study has uncovered that brat function, while dispensable for the larval growth of Drosophila MB axon bundles, is essential to prevent $\mathrm{MB}$ axon retraction during metamorphosis. Interestingly, our clonal analysis has revealed that brat cell autonomously promotes axon maintenance in early born $\gamma$ and $\alpha^{\prime} \beta^{\prime}$ neurons, but that its function is not intrinsically required in $\alpha \beta$ neurons. Such a cell specificity may reflect the use of $\alpha \beta$-specific pathways preventing axon retraction or alternatively a differential stability of late born $\alpha \beta$ axons.

Although the mechanisms regulating axon maintenance are still largely unknown, previous work has shown that downregulating the activity of the small GTPase Rho is essential for the stabilization of axons (Jalink et al., 1994; Billuart et al., 2001; Govek et al., 2005). In a variety of neuronal types, ectopic activation of Rho and its downstream effector Rho-kinase (Rock) causes axon retraction, largely by increasing the contractibility and the stability of the actomyosin cytoskeleton (Govek et al., 2005). In Drosophila MB neurons, both the activation and the expression levels of components of a Rho-dependent signaling pathway controlling axon retraction must be tightly controlled. Ectopic activation of Rhol or Drok leads to MB lobe retraction, a phenotype suppressed by reducing the dosage of other components of the pathway including mys, src, sqh, or drok (Billuart et al., 2001). Conversely, axon overextension phenotypes are observed upon mys or drok loss of function. Several lines of evidence obtained both in vivo and in vitro have indicated that the conserved kinase Src regulates the activity of Rho by phosphorylating the Rho-GAP inhibitory protein p190 (Billuart et al., 2001; Brouns et al., 2001). Consistent with this model, reducing the dosage of src64B significantly suppresses the p190 loss-offunction retraction phenotype observed in $\mathrm{MB}$ neurons (Billuart et al., 2001). Here, we identified Brat as a novel upstream regulator of the Rho-dependent pathway controlling axon retraction, and showed that it is required in vivo to keep the levels of Src64B low during development. This discovery identifies a versatile mechanism that controls neuronal structure maintenance, and demonstrates the importance of post-transcriptional regulations in the modulation of signaling pathway activation.

Tightly controlling the levels of Src and Rho-GTPase is not only important during neuronal development, but also in the context of neural plasticity (Lu et al., 1998; Tolias et al., 2011). Thus, it is tempting to speculate that Brat may help in controlling the balance between stabilization of connectivity patterns and neuronal remodeling in response to experience and learning. To address this possibility, it will be interesting in the future to determine whether Brat is required for the learning and memory processes implicating $\mathrm{MB}$ neurons.

\section{References}

Arama E, Dickman D, Kimchie Z, Shearn A, Lev Z (2000) Mutations in the beta-propeller domain of the Drosophila brain tumor (brat) protein induce neoplasm in the larval brain. Oncogene 19:3706-3716. CrossRef Medline

Bello B, Reichert H, Hirth F (2006) The brain tumor gene negatively regulates neural progenitor cell proliferation in the larval central brain of Drosophila. Development 133:2639-2648. CrossRef Medline

Bénard C, Hobert O (2009) Looking beyond development: maintaining nervous system architecture. Curr Top Dev Biol 87:175-194. CrossRef Medline

Berger C, Harzer H, Burkard TR, Steinmann J, van der Horst S, Laurenson AS, Novatchkova M, Reichert H, Knoblich JA (2012) FACS purification and transcriptome analysis of Drosophila neural stem cells reveals a role for Klumpfuss in self-renewal. Cell Rep 2:407-418. CrossRef Medline

Betschinger J, Mechtler K, Knoblich JA (2006) Asymmetric segregation of 
the tumor suppressor brat regulates self-renewal in Drosophila neural stem cells. Cell 124:1241-1253. CrossRef Medline

Bier E, Vaessin H, Shepherd S, Lee K, McCall K, Barbel S, Ackerman L, Carretto R, Uemura T, Grell E (1989) Searching for pattern and mutation in the Drosophila genome with a P-lacZ vector. Genes Dev 3:12731287. CrossRef Medline

Billuart P, Winter CG, Maresh A, Zhao X, Luo L (2001) Regulating axon branch stability: the role of p190 RhoGAP in repressing a retraction signaling pathway. Cell 107:195-207. CrossRef Medline

Bowman SK, Rolland V, Betschinger J, Kinsey KA, Emery G, Knoblich JA (2008) The tumor suppressors Brat and Numb regulate transitamplifying neuroblast lineages in Drosophila. Dev Cell 14:535-546. CrossRef Medline

Brouns MR, Matheson SF, Settleman J (2001) p190 RhoGAP is the principal Src substrate in brain and regulates axon outgrowth, guidance and fasciculation. Nat Cell Biol 3:361-367. CrossRef Medline

Ceron J, Tejedor FJ, Moya F (2006) A primary cell culture of Drosophila postembryonic larval neuroblasts to study cell cycle and asymmetric division. Eur J Cell Biol 85:567-575. CrossRef Medline

Chang HM, Martinez NJ, Thornton JE, Hagan JP, Nguyen KD, Gregory RI (2012) Trim71 cooperates with microRNAs to repress Cdknla expression and promote embryonic stem cell proliferation. Nat Commun 3:923. CrossRef Medline

Cho PF, Gamberi C, Cho-Park YA, Cho-Park IB, Lasko P, Sonenberg N (2006) Cap-dependent translational inhibition establishes two opposing morphogen gradients in Drosophila embryos. Curr Biol 16:2035-2041. CrossRef Medline

Forbes A, Lehmann R (1998) Nanos and Pumilio have critical roles in the development and function of Drosophila germline stem cells. Development 125:679-690. Medline

Gerber AP, Luschnig S, Krasnow MA, Brown PO, Herschlag D (2006) Genome-wide identification of mRNAs associated with the translational regulator PUMILIO in Drosophila melanogaster. Proc Natl Acad Sci U S A 103:4487-4492. CrossRef Medline

Govek EE, Newey SE, Van Aelst L (2005) The role of the Rho GTPases in neuronal development. Genes Dev 19:1-49. CrossRef Medline

Harris RE, Pargett M, Sutcliffe C, Umulis D, Ashe HL (2011) Brat promotes stem cell differentiation via control of a bistable switch that restricts BMP signaling. Dev Cell 20:72-83. CrossRef Medline

Heisenberg M (2003) Mushroom body memoir: from maps to models. Nat Rev Neurosci 4:266-275. CrossRef Medline

Hoopfer ED, McLaughlin T, Watts RJ, Schuldiner O, O'Leary DD, Luo L (2006) Wlds protection distinguishes axon degeneration following injury from naturally occurring developmental pruning. Neuron 50:883895. CrossRef Medline

Jalink K, van Corven EJ, Hengeveld T, Morii N, Narumiya S, Moolenaar WH (1994) Inhibition of lysophosphatidate- and thrombin-induced neurite retraction and neuronal cell rounding by ADP ribosylation of the small GTP-binding protein Rho. J Cell Biol 126:801-810. CrossRef Medline

Knowles-Barley S, Longair M, Armstrong JD (2010) BrainTrap: a database of 3D protein expression patterns in the Drosophila brain. Database 2010: baq005. CrossRef Medline

Kwon SC, Yi H, Eichelbaum K, Föhr S, Fischer B, You KT, Castello A, Krijgsveld J, Hentze MW, Kim VN (2013) The RNA-binding protein repertoire of embryonic stem cells. Nat Struct Mol Biol 20:1122-1130. CrossRef Medline

Lee T, Lee A, Luo L (1999) Development of the Drosophila mushroom bodies: sequential generation of three distinct types of neurons from a neuroblast. Development 126:4065-4076. Medline

Lehmann R, Nüsslein-Volhard C (1991) The maternal gene nanos has a central role in posterior pattern formation of the Drosophila embryo. Development 112:679-691. Medline
Loedige I, Gaidatzis D, Sack R, Meister G, Filipowicz W (2013) The mammalian TRIM-NHL protein TRIM71/LIN-41 is a repressor of mRNA function. Nucleic Acids Res 41:518-532. CrossRef Medline

Loedige I, Stotz M, Qamar S, Kramer K, Hennig J, Schubert T, Löffler P, Längst G, Merkl R, Urlaub H, Meister G (2014) The NHL domain of BRAT is an RNA-binding domain that directly contacts the hunchback mRNA for regulation. Genes Dev 28:749-764. CrossRef Medline

Lu YM, Roder JC, Davidow J, Salter MW (1998) Src activation in the induction of long-term potentiation in CA1 hippocampal neurons. Science 279:1363-1367. CrossRef Medline

Luo L, O'Leary DD (2005) Axon retraction and degeneration in development and disease. Annu Rev Neurosci 28:127-156. CrossRef Medline

McGuire SE, Mao Z, Davis RL (2004) Spatiotemporal gene expression targeting with the TARGET and gene-switch systems in Drosophila. Sci STKE 2004:pl6. Medline

Muraro NI, Weston AJ, Gerber AP, Luschnig S, Moffat KG, Baines RA (2008) Pumilio binds para mRNA and requires Nanos and Brat to regulate sodium current in Drosophila motoneurons. J Neurosci 28:2099-2109. CrossRef Medline

Neumüller RA, Betschinger J, Fischer A, Bushati N, Poernbacher I, Mechtler K, Cohen SM, Knoblich JA (2008) Mei-P26 regulates microRNAs and cell growth in the Drosophila ovarian stem cell lineage. Nature 454:241245. CrossRef Medline

Olesnicky EC, Bhogal B, Gavis ER (2012) Combinatorial use of translational co-factors for cell type-specific regulation during neuronal morphogenesis in Drosophila. Dev Biol 365:208-218. CrossRef Medline

O’Reilly AM, Ballew AC, Miyazawa B, Stocker H, Hafen E, Simon MA (2006) Csk differentially regulates Src64 during distinct morphological events in Drosophila germ cells. Development 133:2627-2638. CrossRef Medline

Schoenmann Z, Assa-Kunik E, Tiomny S, Minis A, Haklai-Topper L, Arama E, Yaron A (2010) Axonal degeneration is regulated by the apoptotic machinery or a NAD +-sensitive pathway in insects and mammals. J Neurosci 30:6375-6386. CrossRef Medline

Schwamborn JC, Berezikov E, Knoblich JA (2009) The TRIM-NHL protein TRIM32 activates microRNAs and prevents self-renewal in mouse neural progenitors. Cell 136:913-925. CrossRef Medline

Sonoda J, Wharton RP (2001) Drosophila Brain Tumor is a translational repressor. Genes Dev 15:762-773. CrossRef Medline

Tolias KF, Duman JG, Um K (2011) Control of synapse development and plasticity by Rho GTPase regulatory proteins. Prog Neurobiol 94:133148. CrossRef Medline

Wang J, Zugates CT, Liang IH, Lee CH, Lee T (2002) Drosophila Dscam is required for divergent segregation of sister branches and suppresses ectopic bifurcation of axons. Neuron 33:559-571. CrossRef Medline

Watts RJ, Hoopfer ED, Luo L (2003) Axon pruning during Drosophila metamorphosis: evidence for local degeneration and requirement of the ubiquitin-proteasome system. Neuron 38:871-885. CrossRef Medline

Wu JS, Luo L (2006) A protocol for mosaic analysis with a repressible cell marker (MARCM) in Drosophila. Nat Protoc 1:2583-2589. Medline

Wulczyn FG, Cuevas E, Franzoni E, Rybak A (2011) miRNAs need a trim: regulation of miRNA activity by Trim-NHL proteins. Adv Exp Med Biol 700:85-105. CrossRef Medline

Yaniv SP, Issman-Zecharya N, Oren-Suissa M, Podbilewicz B, Schuldiner O (2012) Axon regrowth during development and regeneration following injury share molecular mechanisms. Curr Biol 22:1774-1782. CrossRef Medline

Ye B, Petritsch C, Clark IE, Gavis ER, Jan LY, Jan YN (2004) Nanos and Pumilio are essential for dendrite morphogenesis in Drosophila peripheral neurons. Curr Biol 14:314-321. CrossRef Medline

Zhu S, Perez R, Pan M, Lee T (2005) Requirement of Cul3 for axonal arborization and dendritic elaboration in Drosophila mushroom body neurons. J Neurosci 25:4189-4197. CrossRef Medline 